\title{
Utilidad del examen físico en niños con sospecha de neumonía
}

Does this patient have pneumonia?

Margolis P, Gadomski A. JAMA, 1998;279:308-313

\section{Objetivo}

Determinar la exactitud y precisión del examen físico para diferenciar neumonía de otras infecciones respiratorias bajas en niños.

\section{Diseño}

Revisión sistemática sin agrupar estadísticamente a los resultados debido a la heterogeneidad de la muestra.

\section{Fuente de datos}

Medline de 1982 a 1995. Trabajos en inglés que hubieran usado como test de referencia a la radiología (Rx).

\section{Precisión y exactitud de los signos}

Para evaluar el acuerdo de los signos que aumentan o disminuyen la probabilidad del diagnóstico de neumonía y los que estiman la severidad de la enfermedad, 56 pacientes con síntomas respiratorios bajos fueron examinados por pares de pediatras. Se obtuvieron los siguientes grados de acuerdo:

\begin{tabular}{lc}
\hline Signo & Kappa* \\
\hline Sibilancia audible & 0,70 \\
\hline Color & 0,66 \\
\hline Calidad del llanto & 0,63 \\
\hline Sibilancia espiratoria & 0,63 \\
\hline Uso de músculos accesorios & 0,59 \\
\hline Aspecto y movimientos & 0,54 \\
\hline Sonrisa & 0,51 \\
\hline Atención & 0,49 \\
\hline Tiraje & 0,48 \\
\hline Rales & 0,30 \\
\hline Silbido inspiratorio & 0,29 \\
\hline Espiración prolongada & 0,22 \\
\hline
\end{tabular}

Se reportó el valor de los signos usados aisladamente o combinados como el cociente de probabilidad o likelihood ratio (CP) positivo o negativo.*

\begin{tabular}{lll}
\hline Signos (\#) & \multicolumn{2}{c}{ Cociente de probabilidad } \\
\hline & Positivo & Negativo \\
\hline Taquipnea (\#\#) & $1,5-2,1$ & $0,36-0,5$ \\
\hline Tiraje & $2,4-2,5$ & $0,7-0,8$ \\
\hline Aleteo nasal & 3 & 0,71 \\
\hline Crepitantes & 3,5 & 0,69 \\
\hline Combinación de & 3,4 & 0,1 \\
$\begin{array}{l}\text { Rinorrea, tos, rales } \\
\text { y tiraje(\#\#) }\end{array}$ & IC $95=2,6-4,3$ & IC $95=0,03-0,4$ \\
\hline
\end{tabular}

(\#) Estudios de Reed y col. y de Harari y col. Ninguno de los dos encontró signo alguno que pudiera usarse aisladamente para confirmar o descartar neumonía.

(\#\#) Se considera taquipnea si excede los 60/min en menores de 2 meses, los 50/min entre los 2 y 12 meses y 40/min en mayores de 1 año. Medirla durante 1 minuto (si se lo hace durante 30 segundos se supraestima la frecuencia en 2 a $4 / \mathrm{min}$ ) y hacerlo antes del resto del examen físico. Varía según la fiebre (sube 10/min por cada $\propto$ c de aumento), la atención a su entorno y según esté dormido, despierto o alimentándose.

(\#\#) Estudio de Crain en menores de 2 años.

\section{Conclusión}

El mejor signo para descartar neumonía es la ausencia de taquipnea. Los signos de dificultad respiratoria son buenos para confirmarla. Si todos los signos son negativos, es poco probable que haya neumonía

Fuente de financiamiento: Robert Wood Johnson Foundation.

\section{COMENTARIO}

El diagnóstico de certeza de neumonía se hace con cultivo del aspirado del tracto respiratorio inferior, pero en la práctica clínica la Rx es el test de referencia. La sensibilidad para diferenciar radiológicamente causas bacterianas de virales oscila entre el 42 y el $80 \%$ y la especificidad entre el 42 y el $100 \%$. Esto se debe a la gran variabilidad interobservador y superposición de los patrones radiológicos. Por lo tanto, cuando los autores mencionan los cocientes de probabilidad de que ese hallazgo provenga de un paciente con neumonía no deberían referirse a este diagnóstico sino a hallazgos radiológicos compatibles con neumonía. Uno de los puntos interesantes es que exceptuando a la taquipnea, signo que a priori podría ser considerado como el más objetivo; en la mayoría de los signos clínicos evaluados existe gran variabilidad interobservador, lo que les resta peso para confirmar o descartar cualquier diagnóstico. Signos muy utilizados como la espiración prolongada o los rales mostraron ser signos con mucha variabilidad interobservador.(1)

Esto implica que no son confiables en la práctica clínica ya que cada médico los interpreta de manera muy errática. Por lo tanto uno no debería basarse en signos con tan bajo acuerdo interobservador para predecir la probabilidad de enfermedad. Además sería necesario saber si el par de médicos que evaluó a cada paciente tenían equivalente formación académica, ya que de lo contrario la falta de acuerdo podría explicarse por su diferente experiencia. Para concluir, no hay signo alguno que usado aisladamente sirva para descartar o confirmar la presencia de neumonía, ni siquiera la taquipnea que es el de mejor cociente de probabilidad negativo. Esto significa que ante un paciente sin taquipnea existe una chance entre tres o una entre dos de que provenga de un paciente con neumonía, respecto de un sano. En cuanto a la combinación de signos clínicos el grado de predicción es algo mejor, sin embargo por el momento no parece posible poder establecer algún puntaje clínico (score) que nos permita descartar o confirmar la presencia de neumonía con baja probilidad de error. En conclusión, el cuadro clínico no es un buen 'test diagnóstico' para neumonía, y ante la sospecha de la misma la radiología ayuda a tomar una conducta terapéutica. Aunque la Rx sea imperfecta para diferenciar causas virales de bacterianas, la administración de antibióticos no se discute ante una placa compatible dada la baja morbilidad de los antibióticos y la alta morbimortalidad de las causas bacterianas sin tratamiento adecuado. 


\section{El beneficio del consumo de bajas dosis de alcohol depende del riesgo cardiovascular}

Alcohol consumption and mortality among middle-aged and elderly U.S. adults.

Thun MJ, Peto R, Lopez AD, et al.N Engl J Med 1997; 337:1704-14

\section{Objetivo}

Evaluar los efectos a largo plazo del consumo de distintas dosis de alcohol sobre las causas de muerte.

\author{
Diseño \\ Estudio poblacional prospectivo de cohortes con nueve años de \\ seguimiento.
}

\section{Lugar \\ Estados Unidos}

\section{Participantes}

251.420 mujeres y 236.206 hombres con una edad media de 56 años.

\section{Evaluación de factores de riesgo}

Los participantes respondieron al comienzo del estudio una encuesta sobre consumo de alcohol, tabaco y datos generales de salud. La ingesta de alcohol se evaluó de acuerdo a la cantidad de vasos consumidos (considerando de acuerdo al tipo de bebida una cantidad de $15 \mathrm{gr}$. de alcohol por vaso). Se categorizaron cinco grupos: 1) sin ingesta alcohólica 2) ingesta de menos de un vaso diario y mas de tres por semana 3) un vaso diario 4) dos a tres vasos por día 5) mas de cuatro vasos por día.

\section{Medición de resultados principales}

Las muertes fueron identificadas por el registro nacional de defunciones, y la causa codificada según el código internacional de enfermedades (CIE 9). Se midieron las causas de muerte potencialmente relacionadas con alcohol (cáncer de laringe, esófago, hígado y mama; cirrosis; alcoholismo; muerte violenta) y aquellas relacionadas con enfermedad arterioesclerotica: enfermedad coronaria y cerebrovascular.

\section{Resultados Principales}

Durante los nueve años de seguimiento se registraron 46000 muertes. Las mortalidad cardiovascular representó el $45 \%$ y el $37 \%$ en hombres y mujeres respectivamente, la mortalidad por causas potencialmente relacionadas con alcohol fue a su vez 7 y $15 \%$. Estas causas de muerte fueron tres a siete veces mayores en el grupo con un consumo de mas de cuatro vasos diarios. La mortalidad cardiovascular fue 20 a $40 \%$ menor en hombres RR 0.7 (IC $95 \% 0.7$ a 0.8 ) y en mujeres RR 0.6 (IC 95\% 0.6 a 0.7), que consumían por lo menos un vaso diario con respecto a los no bebedores, existiendo poca relación con el nivel de consumo. La reducción de la mortalidad mas importante ocurrió en el subgrupo de mayores de 60 años con mayor riesgo cardiovascular o que padecieron enfermedad cardiovascular; en ellos esta causa represento el $75 \%$ de la mortalidad global.

\section{Conclusiones}

El consumo moderado de alcohol reduce la mortalidad global a expensas de la enfermedad cardiovascular. El beneficio aumenta con la edad y el riesgo cardiovascular subyacente.

\section{COMENTARIO}

Clásicamente se describe en los estudios sobre consumo de alcohol una curva de mortalidad tipo $\mathrm{J}$; en esta se observa menor mortalidad en la población que consume dosis moderadas de alcohol mientras que la mortalidad es algo mayor en los que no consumen y mucho mayor en los que consumen dosis altas (1) (2). Esto patrón se observa sólo en poblacion de bajo riesgo cardiovascular. En el presente estudio se observa que a medida que el riesgo cardiovascular aumenta el beneficio del consumo moderado de alcohol es mayor. Los resultados poseen validez interna, pero no son completamente generalizables ya que se trata de una población de clase media, con alto nivel de escolaridad y un consumo promedio de alcohol menor al $50 \%$ de La población general norteamericana (3). La protección que brinda el alcohol en este estudio está en parte relacionada a la relativa poca mortalidad de las causas relacionas con alcohol, y esta puede ser muy diferente en un población con otro patrón de consumo. Por ejemplo la baja ocurrencia de muertes violentas encontrada, contrasta con el hecho que en la población entre 15 y 29 años, no incluida en el estu- dio, esta causa representa el $75 \%$ de todas las muertes; tampoco son evaluadas los episodios agudos de consumo (binge) de grandes cantidades de alcohol que pueden contribuir a esta. También es importante evaluar los eventos coronarios y cerebrovasculares no fatales, pero el estudio no se diseñó para registrarlos. Sería interesante realizar un ensayo clínico controlado en prevención secundaria con pacientes con enfermedad coronaria, ya que por el alto riesgo basal podrían tener un importante beneficio. Otra línea de investigación posible e interesante es la sintesis de un principio activo del alcohol que conserve el efecto beneficioso sobre el corazón sin su efecto deletéreo. El alcohol posee efectos beneficiosos en aquellos sujetos que padecen enfermedad arterioesclerotica y/o mayor riesgo cardiovascular; cuando el riesgo es intermedio o bajo el beneficio es marginal, y cuando el alcohol es consumido a altas dosis su efecto es claramente perjudicial (4). No hay ninguna sociedad científica reconocida que actualmente recomiende la prescripción de alcohol, esta solamente puede ser evaluada por el medico en su consultorio en virtud al riesgo y características individuales de cada paciente.

\section{Dr. Augusto Granel}

Unidad de Medicina Familiar y Preventiva Hospital Italiano de Buenos Aires

Referencias

2. Camargo C, Hennekens C, Gaziano M, et al.Prospective study of moderate alcohol consumption and mortality in US male physicians. Arch Intern Med 1997; 157: 79-85

3. Potter J. Hazards and benefits of alcohol. N Engl J Med 1997; 337: 1763-1764

4. Friedman G, Klatsky A. Is alcohol good for your health?. N Engl J Med 1993;323:1882-1883 